\title{
Genetic Diversity for Yield and Yield Contributing Characters of Short Statured Maize Inbred Lines
}

\author{
Mohammad Motasim Billah', Lutful Hassan², Mohammad Quamrul Islam Matin 1*, \\ Mohammad Zahirul Alam Talukder'1, Mohammad Khorshed Alam ${ }^{1}$ \\ ${ }^{1}$ Plant Breeding Division, Bangladesh Agricultural Research Institute, Gazipur, Bangladesh \\ ${ }^{2}$ Dept. of Genetics and Plant Breeding, Bangladesh Agricultural University (BAU), Mymensingh, Bangladesh \\ Email: motasimbari@yahoo.com, lutfulhassan@yahoo.co.uk, ^quamrul_islam76@yahoo.com, zahirbari@yahoo.com, \\ nobodybangla@yahoo.com
}

How to cite this paper: Billah, M.M., Hassan, L., Matin, M.Q.I., Talukder, M.Z.A. and Alam, M.K. (2021) Genetic Diversity for Yield and Yield Contributing Characters of Short Statured Maize Inbred Lines. American Journal of Plant Sciences, 12, 934-945.

https://doi.org/10.4236/ajps.2021.126063

Received: April 11, 2021

Accepted: June 26, 2021

Published: June 29, 2021

Copyright (c) 2021 by author(s) and Scientific Research Publishing Inc. This work is licensed under the Creative Commons Attribution International License (CC BY 4.0).

http://creativecommons.org/licenses/by/4.0/

\begin{abstract}
Genetic diversity is one of the useful tools to select appropriate lines for hybridization. Twenty short-statured maize inbred lines were taken for present study, which were collected from CIMMYT India and Mexico through Plant Breeding Division, Bangladesh Agricultural Research Institute (BARI), Gazipur. This experiment was conducted from November 2015 to April 2016 to identify parental lines to produce single cross short statured maize hybrids. From the genetic diversity studies, the importance of both additive and non-additive gene actions for the expression of yield and yield contributing characters were found. Values of vector I and II revealed that both the vectors had positive values for date of silking, plant height, rows/cob, grains/row and yield. These results indicated that these five characters had highest contribution towards divergence. Based on the relative magnitude of $\mathrm{D}^{2}$ values; 20 inbred lines were grouped into five clusters. Seven inbred lines were selected on the basis of genetic diversity and per se performance which will be crossed separately in a half-diallel fashion to develop hybrids.
\end{abstract}

\section{Keywords}

Genetic Diversity, Inbred Lines, Maize

\section{Introduction}

"Maize (Zea mays L., $2 \mathrm{n}=20$ )" is one of the most important cereal crops in the world. It is a major food, feed and industrial crop both in developed and developing countries. The area, production and yield of maize have increased many 
folds over the last 50 years. Maize production and consumption both increase at the rate of $3.5 \%$ annually [1]. The yield potential of this crop is almost twice than that of rice and wheat. Maize yield is higher because it is responsive to better crop management, has wider adaptability, and can be grown better than wheat and rice in stress conditions [2]. It is also known as Indian corn or corn in America [3] [4]. Globally, this crop is known as "maize" both scientifically as well as commercially. Maize is thought to be originated from teosinte, a prehistoric wild grass from Mexico and Guatemala [5]. It is a cereal that was domesticated by indigenous people in Mesoamerica in prehistoric times and between 1700 and $1250 \mathrm{BC}$ and then the crop was spread through much of the America. In the late 15th and early 16th centuries, explorers and traders brought maize to Europe and other countries from the USA. Having originated in the tropics and evolved there as an important food yielding plant, it is now grown at up to $58^{\circ} \mathrm{N}$ latitude in Canada and in the Russian Federation without interruption through the temperate and up to $40^{\circ} \mathrm{S}$ latitude in Chile and Argentina [6]. Most of the maize crop is grown at moderate altitudes, but it is also grown below sea level in the Caspian plain and up to $3800 \mathrm{~m}$ high in the Andean mountains. The crop continues to expand to new areas and environments [3]. In Asia, maize has been recorded the fastest annual growth accounting for around 4 percent. In spite of increased production, increasing and competing demands of maize it is necessary to invest more for its research. In Bangladesh, human consumption of corn is mainly limited to roasted green cobs. It is now third important cereal crop after rice and wheat. But recently gaining popularity among the farmers is mainly due to higher yield, more economic return, and multiple uses [7]. Using introduced and locally developed inbred lines BARI has so far developed 11 hybrid maize varieties of various kinds and some of which are now being cultivated commercially. The yield potentiality of the released composites and hybrids ranges from 4.5 to 7.0 tons/ha and 10.5 to 12.5 tons/ha, respectively. The yield gap between composite and hybrid drives the farmers to shift from composites to hybrids. Due to its high yield potentiality, increasing demand for maize in Bangladesh can be met with the use of hybrid varieties. In Bangladesh, the sole maize (except popcorn and adulteration in wheat flour) is used up by poultry industries. In our country maximum maize produces in rabi season, rainy and stormy weather is common phenomenon at pre mature stage. Though plant height is positively correlated with yield, excess height of hybrid maize causes lodging at pre mature stage while weather is rainy and stormy. So we have to develop dwarf hybrid maize varieties to check lodging to keep yield loss at the minimum level. In view of the above importance, to develop short statured maize variety genetic diversity following gene action and combining ability (GCA, SCA) studies was carried out [8] [9] [10] [11].

\section{Materials and Methods}

The experiment was carried out at the central research farm of Bangladesh Agricultural Research Institute (BARI), Gazipur to select promising and diverse 
inbred lines for hybridization during November 2012 to May 2013. Twenty maize inbred lines were collected from CIMMYT India, CIMMYT Mexico through Plant Breeding Division of BARI. The pedigree were as follows CML20-2-B (H08R-N8205-4), CML27-2-B (H08R-N8205-7), CML28-2-B (H08R-N8205-9), CML30-2-B (H08R-N8205-13), CML31-2-B (H08R-N8205-15), CML32-2-B (H08R-N8205-17), CML33-1-B (H08R-N8205-18), CML41-2-B (H08R-N8205-20), CML51-2-B (H08R-N8205-22), CML58-1-B (H08R-N8205-23), CML70-2-B (H08R-N8205-28), CML71-2-B (H08R-N8205-31), CML72-1-B (H08R-N8205-32), CML112-1-B (H08R-N8205-38), CML113-1-B (H08R-N8205-39), CML116-1-B (H08R-N8205-42), CML121-1-B (H08R-N8205-43), CML122-1-B (H08R-N8205-44), CML124-1-B (H08R-N8205-45), CML124-2-B (H08R-N8205-46). Among them the inbreds CML31-2-B, CML32-2-B, CML33-1-B, CML41-2-B, CML72-1-B, CML116-1-B, CML124-2-B were selected and designated as parents SP05, SP06, SP03, SP04, SP02, SP01 and SP07, respectively. The experiment was laid out following alpha lattice design [12] with 3 replications. Seeds were sown on 05 December, 2014.

The experimental fields were prepared by ploughing with tractor followed by harrowing and laddering to bring desirable tilth. Fertilizers recommended for inbred were applied @120,80, 80, 20, 5, $1 \mathrm{~kg} \cdot \mathrm{ha}^{-1}$ of $\mathrm{N}, \mathrm{P}_{2} \mathrm{O}_{5}, \mathrm{~K} 2 \mathrm{O}, \mathrm{S}, \mathrm{Zn}, \mathrm{B}$, respectively. One third of nitrogen and the whole amount of other fertilizers were applied to the soil at the time of final land preparation. The experiments for each group of genotype were planted in two rows of $5 \mathrm{~m}$. length, row to row and plant to plant spacing of $60 \mathrm{~cm}$ and $20 \mathrm{~cm}$, respectively, Sowing was done in furrows with two seeds per hill. The seedlings emerged five to seven days after sowing. Seedlings were thinned keeping one seedling per hill after two weeks of emergence.

Standard agronomic practices were followed in trial management [13] and necessary intercultural operations were done during the crop growing period to ensure the normal growth and development of the plants.

Ten randomly selected competitive plants at field maturity (5 from each row in a plot of each genotype) excluding any plant surrounding by a missing hill were used for receding observations on the following parameters: days to tasseling (DT), days to silking (DS), plant height $(\mathrm{PH})$, ear height $(\mathrm{EH})$, ear length $(E L)$, ear diameter (ED), number of rows $\operatorname{cob}^{-1}(\mathrm{R} / \mathrm{C})$, number of seeds row ${ }^{-1}$ $(\mathrm{S} / \mathrm{R})$, thousand grain weight $(\mathrm{TGW})$, grain yield plant $^{-1}(\mathrm{Y} / \mathrm{P})$.

\section{Results and Discussion}

\section{Mean performance of short statured maize inbred lines}

Mean performance of the inbred lines presented in Table 1. The highest grain yield was observed from maize line 16, followed by maize lines 13, 20, 1 and 2 . Yield components such as ear length and diameter, number of kernels per ear and thousand grain weights were found higher in lines 1, 2, 13, 14, 19, 20 but some of them were late in anthesis time and medium in plant stature. 
Table 1. Mean performance of 20 short statured maize inbred lines.

\begin{tabular}{|c|c|c|c|c|c|c|c|c|c|c|c|}
\hline $\begin{array}{l}\text { Inbred } \\
\text { lines }\end{array}$ & $\begin{array}{c}\text { Selected } \\
\text { genotypes }\end{array}$ & DT & DS & PH & $\mathrm{EH}$ & EL & ED & $\mathrm{R} / \mathrm{C}$ & S/R & TGW & $\mathrm{Y} / \mathrm{P}$ \\
\hline 1 & & 113 & 117 & 92.0 & 39.0 & 15.6 & 3.67 & 10.8 & 21.0 & 280 & 260 \\
\hline 2 & & 97 & 100 & 88.0 & 20. & 6.10 & 3.63 & 10.0 & 14.1 & 280 & 260 \\
\hline 3 & & 99 & 103 & 72.0 & 21.7 & 5.0 & 3.13 & 10.0 & 10.4 & 240 & 220 \\
\hline 4 & & 99 & 103 & 68.3 & 18.7 & 7.0 & 2.10 & 10.5 & 11.5 & 180 & 190 \\
\hline 5 & SP05 & 88 & 94 & 49.3 & 12.7 & 7.5 & 3.77 & 14.0 & 15.3 & 240 & 190 \\
\hline 6 & SP06 & 100 & 105 & 74.7 & 20.3 & 8.4 & 3.67 & 12.8 & 14.2 & 240 & 220 \\
\hline 7 & SP03 & 96 & 99 & 66.3 & 18.3 & 7.6 & 4.27 & 13.2 & 18.2 & 240 & 210 \\
\hline 8 & SP04 & 95 & 97 & 70.0 & 19.3 & 9.4 & 4.13 & 14.4 & 16.2 & 240 & 250 \\
\hline 9 & & 87 & 89 & 99.0 & 26.0 & 7.7 & 3.67 & 10.6 & 14.7 & 220 & 240 \\
\hline 10 & & 95 & 99 & 81.0 & 25.3 & 8.4 & 4.20 & 11.7 & 18.6 & 240 & 220 \\
\hline 11 & & 95 & 98 & 89.3 & 30.3 & 8.0 & 4.10 & 12.0 & 15.5 & 240 & 220 \\
\hline 12 & & 104 & 107 & 88.0 & 32.7 & 11.6 & 3.67 & 12.4 & 16.4 & 200 & 180 \\
\hline 13 & SP02 & 94 & 97 & 90.3 & 23.7 & 10.5 & 4.10 & 12.3 & 19.5 & 310 & 300 \\
\hline 14 & & 87 & 89 & 94.7 & 24.7 & 10.4 & 3.77 & 11.6 & 14.2 & 340 & 200 \\
\hline 15 & & 113 & 116 & 90.3 & 29.3 & 11.3 & 3.87 & 12.0 & 20.4 & 240 & 200 \\
\hline 16 & SP01 & 94 & 97 & 85.3 & 30.0 & 12.4 & 4.33 & 14.1 & 21.4 & 270 & 330 \\
\hline 17 & & 97 & 101 & 66.0 & 20.6 & 7.5 & 4.10 & 12.3 & 15.0 & 310 & 150 \\
\hline 18 & & 104 & 108 & 122.3 & 44.3 & 10.5 & 4.17 & 12.0 & 13.8 & 240 & 100 \\
\hline 19 & & 106 & 110 & 106.0 & 47.0 & 13.6 & 3.80 & 10.8 & 16.8 & 290 & 180 \\
\hline 20 & SP07 & 88 & 91 & 86.3 & 26.7 & 9.8 & 3.07 & 12.6 & 16.2 & 290 & 280 \\
\hline Mean & & 97.55 & 101.00 & 73.21 & 36.88 & 9.02 & 3.76 & 11.76 & 15.87 & 261.00 & 210.50 \\
\hline Cv\% & & 7.78 & 7.78 & 20.51 & 33.36 & 28.69 & 13.81 & 11.76 & 21.26 & 14.76 & 27.20 \\
\hline
\end{tabular}

$\mathrm{DT}=$ Days to tasseling (50\%), DS = Days to silking $(50 \%), \mathrm{PH}=$ Plant height $(\mathrm{cm}), \mathrm{EH}=$ Ear height $(\mathrm{cm})$, $\mathrm{EL}=$ Ear length $(\mathrm{cm}), \mathrm{ED}=$ Ear diameter $(\mathrm{cm}), \mathrm{R} / \mathrm{C}=$ Rows per cob, $\mathrm{S} / \mathrm{R}=$ Seeds per Row, $\mathrm{TGW}=$ Thousand grains weight $(\mathrm{gm})$ and $\mathrm{Y} / \mathrm{P}=$ Yield/plant $(\mathrm{gm})$.

The most important yield contributing characters in maize are ear length and diameter. Ear length and diameter ranged from $5.0 \mathrm{~cm}$ to $15.6 \mathrm{~cm}$ and $2.1 \mathrm{~cm}$ to $4.33 \mathrm{~cm}$, respectively. The highest number of kernels/seeds per row was observed in line 16 followed by 15 and 1 . The highest number of rows per cob was observed in line 8 followed by 15 and 1 . Inbred line 14 produced the bold sized grain and showed the highest thousand grain weight, whereas line 4 gave the lowest thousand grain weights. Some of the inbred lines had thousand grain weights above or near $250 \mathrm{~g}$ which is also a desirable character.

Duration of pollen shedding and silking ranged from 87 to 113 and 89 to 117 days, respectively. The line 1 took the longest on the other hand the line 9 took the shortest period of time for pollen shedding and silking. Generally, pollen shedding started earlier than silking. Anthesis and silking interval (ASI) of all 
the inbred lines evaluated in this experiment ranged from 2-4 days which could be considered as a good trait. Plant height was found highest in line 18 followed by 19 and 09 and it was found lowest in 5 followed by 7 and 17. Ear height ranged from 12.7 to $47.0 \mathrm{~cm}$ among the tested inbreds. Inbred line 5 also showed the shortest ear height followed by 7 and 4 . In all the entries, ear placement was at or near the midpoint of the plant which is a desirable character.

Construction of scatter diagram of 20 short statured maize inbred lines

The analysis of variance showed significant variations among all the inbred lines for all the ten characters studied. Based on the values of principal component scores 2 and 1 obtained from the principal component analysis, a two-dimensional scatter diagram $\left(\mathrm{Z}_{2}-\mathrm{Z}_{1}\right)$ using component score 1 as $\mathrm{X}$-axis and component score 2 as $\mathrm{Y}$-axis was constructed, which has been presented in Figure 1. The genotypes were distributed in 5 clusters based on their position in scatter diagram suggesting sufficient variabilities among them. It was also revealed that the inbred lines of cluster III was more diverse from the inbred lines of cluster II. This was an illustration by [14] [15].

Cluster analysis of 20 short statured maize inbred lines

Clustering pattern could be utilized in choosing parents for cross combination that could be produced variability for selection [13]. Genetic diversity of 20 inbred lines was studied using Mahalanobis's $\mathrm{D}^{2}$ statistics. All the 20 inbred lines were grouped into 5 clusters. The distribution pattern indicated that maximum 7 inbred lines were included in cluster III followed by 6 in cluster IV. The remainders have been distributed in three clusters: 2 in each cluster I and II, 3 in

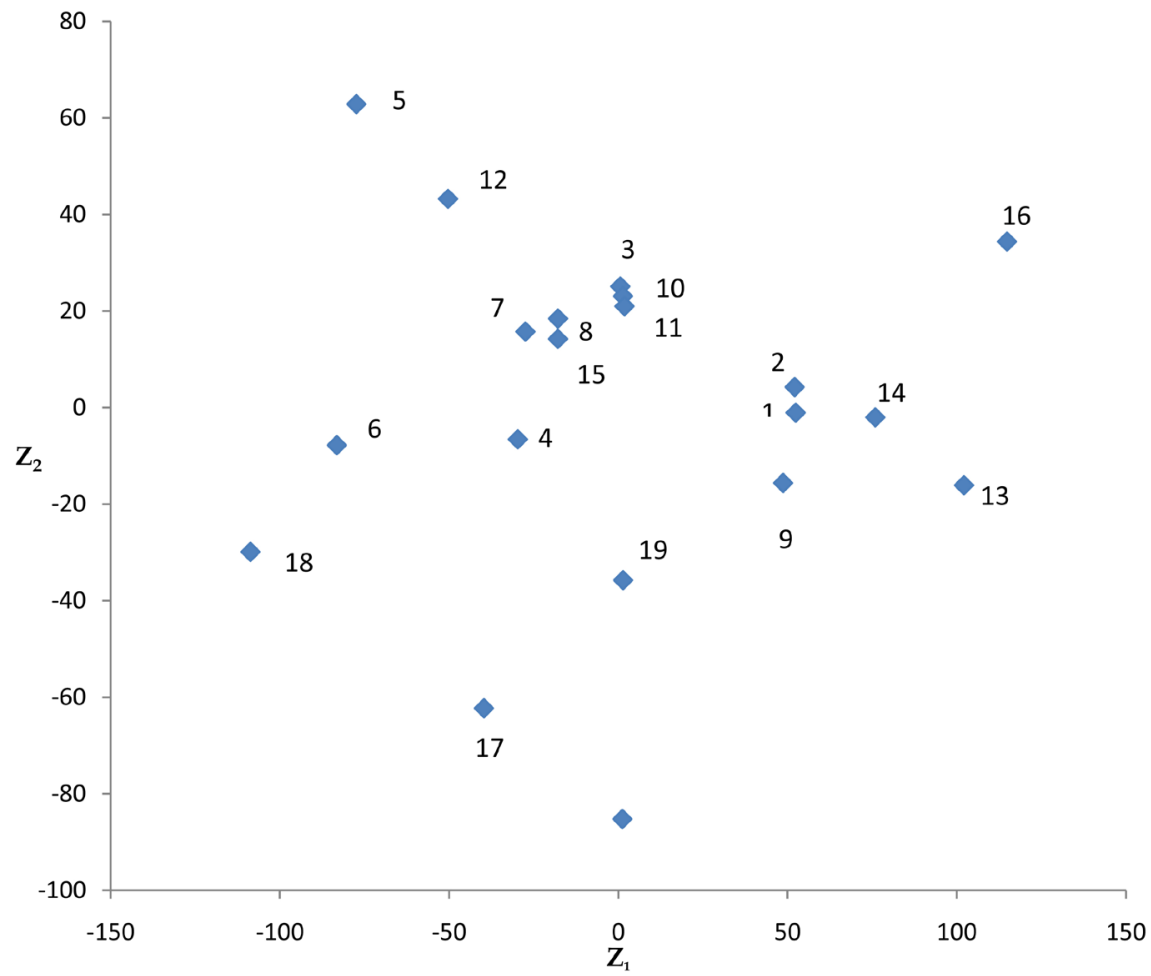

Figure 1. Scatter distribution of 20 short statured maize inbred lines. 
cluster V. Clusters III and IV comprised 35\% and 30\% of the total inbred lines (Table 2).

[16] classified five in divergence of maize inbreds, [17] six clusters of sixty four maize inbreds, [18] seven clusters of thirty nine maize genotypes, [19] nine clusters of forty three maize inbred line [20] seven cluster of thirty nine bread wheat genotypes. Similarly some other authors such as [21] [22] [23] mentioned similar findings in their studies.

Principal component analysis (PCA) of 20 short statured maize inbred lines

Ten characters were considered for genetic diversity analysis. Eigen values of ten principal axis and percentage of total variation accounting for them obtained from the principal component analysis are presented in Table 3 . The results revealed that the first principal axis largely accounted for the variation among the genotypes which alone contributed $37.92 \%$ of the variations followed by the $2^{\text {nd }}$ axis $(22.69 \%)$ while the first five Eigen values for the principal component axes of genotype accounted for $92.05 \%$ of the total variation among 10 characters describing 20 genotypes while the top two accounted for $60.61 \%$.

Principal Coordinate analysis (PCO) of 20 short statured maize inbred lines

Table 2. Distribution of 20 short statured maize inbred lines in five different clusters.

\begin{tabular}{ccc}
\hline Clusters & Number of genotypes & Inbred lines included in different clusters \\
\hline I & 2 & L06, L18 \\
II & 2 & L05, L12 \\
III & 7 & L03, L04, L07, L08, L10, L11, L15 \\
IV & 6 & L01, L02, L09, L13, L14, L16 \\
V & 3 & L17, L19, L20 \\
\hline
\end{tabular}

Table 3. Eigen values and percentage of variation in respect of 10 component characters of 20 short statured maize inbred lines.

\begin{tabular}{cccc}
\hline Principal component axis & Eigen values & \% of total variation & Cumulative percentages \\
\hline I & 3.7923 & 37.92 & 37.92 \\
II & 2.2695 & 22.69 & 60.61 \\
III & 1.4968 & 14.97 & 75.58 \\
IV & 1.0220 & 10.22 & 85.80 \\
V & 0.6251 & 6.25 & 92.05 \\
VI & 0.4280 & 4.28 & 96.33 \\
VII & 0.2160 & 2.16 & 98.49 \\
VIII & 0.1209 & 1.21 & 99.70 \\
IX & 0.0261 & 0.26 & 99.96 \\
X & 0.0035 & 0.03 & 99.99 \\
\hline
\end{tabular}


Principal Coordinate Analysis (PCO) was done to get inter genotypic distances. The highest inter genotypic distance (1.683) was observed between the lines L20 and L5 followed by the lines L16 and L5 (1.646) and lines L5 and L13 (1.644) (Table 4). The lowest distance was observed between the lines L3 and L15 (0.1897) followed by the lines L11 and L10 (0.2688) and lines L15 and L12 (0.2701) (Table 5). The difference between the highest and the lowest inter genotypic distance indicated the existence of variability among 20 inbred lines of maize.

Average intra and inter cluster distance of 20 short statured maize inbred lines

The inter cluster distance (Table 6) was maximum between cluster II and V (28.19) followed by cluster II and IV (24.62) and then between cluster I and IV (19.72). While the inter cluster distance was minimum between cluster I and III (9.18) followed by cluster IV and V (9.65) and then between cluster II and III (12.09). The maximum value of inter cluster distance indicated that the lines belonging to cluster II and V were far diverged. Similarly the higher inter cluster

Table 4. Ten highest inter genotypic distances among 20 short statured maize inbred lines.

\begin{tabular}{cc}
\hline Genotypic combination & Distance $\left(\mathrm{D}^{2}\right.$ Values $)$ \\
\hline L20 and L05 & 1.6831 \\
L16 and L05 & 1.6461 \\
L05 and L13 & 1.6443 \\
L18 and L02 & 1.4630 \\
L03 and L01 & 1.4401 \\
L04 and L01 & 1.4002 \\
L18 and L03 & 1.3990 \\
L18 and L04 & 1.3892 \\
L06 and L08 & 1.3587 \\
L19 and L03 & 1.3362 \\
\hline
\end{tabular}

Table 5. Ten lowest inter genotypic distances among the 20 short statured maize inbred lines.

\begin{tabular}{cc}
\hline Genotypic combination & Distance $\left(\mathrm{D}^{2}\right.$ Values $)$ \\
\hline L03 and L15 & 0.1897 \\
L11 and L10 & 0.2688 \\
L15 and L12 & 0.2701 \\
L14 and L13 & 0.3009 \\
L10 and L08 & 0.3894 \\
L16 and L14 & 0.3934 \\
L17 and L07 & 0.4153 \\
L16 and L13 & 0.4187 \\
L03 and L02 & 0.4327 \\
L15 and L10 & 0.4374
\end{tabular}


Table 6. Average intra and inter cluster distances $\left(D^{2}\right)$ for 20 short statured maize inbred lines.

\begin{tabular}{cccccc}
\hline Cluster number & I & II & III & IV & V \\
\hline I & 1.044 & & & & \\
II & 12.24 & 1.2139 & & & \\
III & 9.18 & 12.09 & 0.662 & & \\
IV & 19.72 & 24.62 & 12.97 & 0.6577 & \\
V & 19.52 & 28.19 & 16.78 & 9.65 & 0.8562 \\
\hline
\end{tabular}

values between cluster II and IV, cluster I and V, I and IV indicated the lines belonging to each pair of cluster we real so far diverged.

The intra-cluster distances were calculated from these inter-genotypic distances as suggested by [24]. The enormity of the intra-cluster distances didn't recorded proportional to the number of genotypes in each clusters (Table 6). In the present study it was found that although cluster III composed of largest number of lines, 7 (Table 2) but intra-cluster distance was not necessarily the highest (Table 6). The highest intra-cluster distance was recorded in cluster II (1.214) containing 2 lines (L5, L12) followed by cluster I (1.044) also containing 2 lines (L6 and L18). The least intra-cluster distance was observed in cluster IV (0.6577) consisting of 06 lines (L1, L2, L09, L13, L14 and L16).

\section{Cluster means of 20 short statured maize inbred lines}

Cluster mean for 10 characters are presented in Table 7. Cluster I composed of two lines (L6 and L18), scored highest mean for date of tasseling (102.00), date of silking (106.50), plant height (98.50), ear height (32.30) and ear diameter (3.92). Second highest mean was obtained from character Rows/cob (12.40).

Cluster II composed of two lines (L5 and L12) gave highest mean for rows/cob (13.20) and seed/row (18.35), second highest mean was obtained from character ear length (9.55).

Cluster III composed of seven lines (L3, L4, L7, L8, L10, L11 and L15) did not gave highest mean for any character but second highest mean was found for date of tasseling (98.86), date of silking (102.14) and seed/row (15.97).

Cluster IV composed of six lines (L1, L2, L9, L13, L14 and L16) and gave highest mean for yield/plant (280.00) and second highest mean value were obtained from ear diameter (3.86) and thousand grain weight (286.67).

Cluster V composed of 3 lines (L17, L19 and L20) and was found to give highest mean for 1000 seed wt. (313.33) and ear length (10.50), second highest mean was found for plant height (88.90), ear height (30.77).

The highest mean values for some expected yield contributing traits were identified in cluster I, II, IV and V, the second highest values of some desirable traits were grouped in cluster III, IV. Therefore, selection for higher yield can safely done from these clusters.

Latent vectors of 20 short statured maize inbred lines

Contribution of characters towards divergence of the genotypes obtained from principal component analysis (PCA) was presented in Table 8. Values of vector 
Table 7. Cluster means for 10 characters of 20 short statured maize inbred lines.

\begin{tabular}{lccccc}
\hline Character & I & II & III & IV & V \\
\hline 1. DT & 102.00 & 96.00 & 98.86 & 95.50 & 96.67 \\
2. DS & 106.50 & 100.50 & 102.14 & 98.50 & 100.00 \\
3. PH & 98.50 & 68.65 & 76.74 & 88.82 & 88.90 \\
4. EH & 32.30 & 22.70 & 23.27 & 27.57 & 30.77 \\
5. EL & 8.85 & 9.75 & 8.60 & 9.92 & 10.70 \\
6. ED & 3.92 & 3.72 & 3.69 & 3.86 & 3.657 \\
7. R/C & 12.40 & 13.20 & 11.97 & 10.73 & 11.90 \\
8. S/R & 14.0 & 18.35 & 15.97 & 15.82 & 15.33 \\
9. TGW & 240.00 & 190.00 & 242.86 & 286.67 & 313.33 \\
10. Y/P & 115.00 & 170.00 & 204.29 & 280.00 & 176.67 \\
\hline
\end{tabular}

DT $=$ Days to Tasseling (50\%), DS = Days to Silking (50\%), PH = Plant Height $(\mathrm{cm}), \mathrm{EH}=$ Ear Height $(\mathrm{cm})$, $\mathrm{EL}=$ Ear Length $(\mathrm{cm}), \mathrm{ED}=$ Ear Diameter $(\mathrm{cm}), \mathrm{R} / \mathrm{C}=$ Rows per $\mathrm{Cob}, \mathrm{S} / \mathrm{R}=$ Seeds per Row, TGW = Thousand Grains Weight (gm) and Y/P = Yield/Plant (gm).

Table 8. Latent vectors for 10 characters of 20 short statured maize inbred lines.

\begin{tabular}{ccc}
\hline Character & Vector I & Vector II \\
\hline 1. DT & -0.5865 & -1.3242 \\
2. DS & 0.4786 & 1.2913 \\
3. PH & 0.2587 & 0.0106 \\
4. EH & -0.1720 & 0.4004 \\
5. EL & -1.3278 & -1.3202 \\
6. ED & -1.7260 & -0.4796 \\
7. R/C & 0.8771 & 1.4469 \\
8. S/R & 1.0137 & 0.4056 \\
9. TGW & -0.2023 & 0.0849 \\
10. Y/P & 0.0294 & 0.0460 \\
\hline
\end{tabular}

DT $=$ Days to Tasseling (50\%), DS = Days to Silking (50\%), PH = Plant Height $(\mathrm{cm}), \mathrm{EH}=$ Ear Height $(\mathrm{cm})$, $\mathrm{EL}=$ Ear Length $(\mathrm{cm}), \mathrm{ED}=$ Ear Diameter $(\mathrm{cm}), \mathrm{R} / \mathrm{C}=$ Rows per $\mathrm{Cob}, \mathrm{S} / \mathrm{R}=$ Seeds per Row, TGW = Thousand Grains Weight (gm) and Y/P = Yield/Plant (gm).

I and II revealed that both the vectors had positive values for date of silking, plant height, rows/cob, grains/row and yield. These results indicated that these five characters had highest contribution towards divergence and negative values in both the vectors for date of tasseling, ear length and ear diameter these three characters had the least contribution towards divergence among the 20 short statured maize inbred lines. In vector I (the major axis of differentiation) other characters responsible for genetic divergence were ear height and thousand grain weight showed negative vector values and in vector II (the second axis of differentiation) they showed positive vector values. It was supported by several authors such as [14] [17] [25] [26] [27]. 


\section{Conclusions}

Among the 20 short-statured inbreds, the performance of inbred lines 16 and 13 showed high yield with different yield contributing traits. Plant and ear height was found the highest in inbred line18 followed by 19 and 09 and it was found lowest in 05 followed by 07 and 17. Plant height ranged from $49.30 \mathrm{~cm}$ to 122.30 $\mathrm{cm}$ and ear height ranged from $12.7 \mathrm{~cm}$ to $47.0 \mathrm{~cm}$. In all the lines, ear placement was at or near the midpoint of the plant which was a desirable character. In cluster analysis maximum of 07 short-statured inbred lines were included in cluster III followed by 06 in cluster IV. These two clusters contained $65 \%$ of the total inbred lines. The inter-cluster distance was maximum between cluster II and V (28.19) followed by cluster II and IV (24.62) and then between cluster I and IV (19.72). While the inter-cluster distance was minimum between cluster I and III (9.18) followed by cluster IV and V (9.65) and then between cluster II and III (12.09). Cluster II and III gave the lowest mean for plant and ear height. The highest cluster mean for some desired yield contributing characteristics were observed in cluster I, II, IV and V, second highest value of some desired character recorded in cluster III, IV. Both the vectors I and II had positive values for yield per plant, days to silking, plant height, rows per cob, seeds per row indicated that these five characters had the highest contribution and had negative value for the date of tasseling, ear length and ear diameter indicated that these three characters had the lowest contribution towards the divergence among 20 inbred lines.

Out of twenty inbreds, seven short statured maize inbred lines such as SP05, SP06, SP03, SP04, SP02, SP01, SP07 were selected for crossing and evaluation considering overall performance, yield performance, cluster distance, cluster mean and contribution of the characters towards divergence.

\section{Conflicts of Interest}

There were no conflicts of interests.

\section{References}

[1] Anonymous (2008) Annual Report. Bangladesh Agricultural Research Institute, BARI, Gazipur, 25-30.

[2] Paliwal, R.L., Granados. G., Latfitte, H.R. and Violic, A.D. (2000) Tropical Maize-Improvement and Production by FAO Plant Production and Protection No. 28. Rome, 363.

[3] Kochhar, S.L. (1986) Tropical Crops. A Textbook of Economic Botany. Macmillan Publishers, Hong Kong, 88-95.

[4] Purseglove, J.W. (1992) Tropical Crops: Monocotyledons. Longman Scientific and Technical, New York, 300-305.

[5] Sprague, G. and Dudley, W. (1988) Corn and Corn Improvement. 3rd Edition, American Society of Agronomy, Inc., Madison. https://doi.org/10.2134/agronmonogr18.3ed

[6] Hallauer, A.R. and Miranda, F. (1988) Quantitative Genetics in Maize Breeding. 
Iowa State University Press, Ames, IOWA.

[7] Matin, M. Q. I., Rasul, M. G., Islam, A.K.M.A., Mian, M.A.K., Ivy, N.A. and Ahmed, J.U. (2017) Genotype Environment Interaction in Maturity and Yield of Hybrid Maize (Zea mays L.). Journal of Agricultural Science, 2, 29-40.

[8] Fan, X.M., Tan, J., Yang, J.Y. and Chen, H.M. (2004) Combining Ability and Heterotic Grouping of Ten Temperate, Subtropical and Tropical Quality Protein Maize Inbred. Istituto Sperimentale per la Cerealicultura, Bergamo, 78-86.

[9] Melani, M.D. and Carena, M.J. (2005) Alternative Maize Heterotic Pattern for the Northern Corn Belt. Crop Science, 45, 2186-2194.

https://doi.org/10.2135/cropsci2004.0289

[10] Barata, C. and Carena, M. (2006) Classification of North Dakota Maize Inbred Lines Intoheterotic Groups Based on Molecular and Testcross Data. Euphytica, 151, 339-349. https://doi.org/10.1007/s10681-006-9155-y

[11] Bello, O.B. and Olaoye, G. (2009) Combining Ability for Maize Grain Yield and Other Ronomic Characters in a Typical Southern Guinea Savanna Ecology of Nigeria. African Journal of Biotechnology, 11, 2518-2522.

[12] Patterson, H.D., Williams, E.R. and Hunter, E.A. (1978) Block Design for Variety Trials. Journal of Agricultural Science (Cambridge), 90, 395-400. https://doi.org/10.1017/S0021859600055507

[13] Quayyum, M.A. (1993) Bhuttar Chash Paddhati (in Bengali). In: Chowdhury, M.K and Islam, M.A., Eds., Bhuttar Utpadan o Babahar, Bangladesh Agricultural Research Institute, Gazipur, 43-48.

[14] Endang, S., Andani, S. and Nasoetion, H. (1971) Multivariate Classification of Some rice (Oryza sativa L.) Varieties and Strain on Yield Components. International Rice Communication Newsletter, 20, 26-34.

[15] Timothy, D.H. (1963) Genetic Diversity, Heterosis and the Use of Exotic Stocks in Maize in Columbia. Statistical Genetics and Plant Breeding Symposium, Raleigh, 1961, 581-591.

[16] Ivy, N.A., Uddin, M.S., Sultana, R. and Masud, M.M. (2007) Genetic Divergence in Maize (Zea mays L.). Bangladesh Journal of Plant Breeding \& Genetics, 20, 53-56. https://doi.org/10.3329/bjpbg.v20i1.17027

[17] Matin, M.Q.I., Rasul, M.G., Islam, A.K.M.A., Mian, M.A.K., Ivy, N.A. and Ahmed, J.U. (2017) Study of Genetic Diversity in Maize (Zea mays L.) Inbreds. Plant, 5, 31-35. https://doi.org/10.11648/j.plant.20170502.11

[18] Zaman, M.A. and Alam, M.A. (2013) Genetic Diversity in Exotic Maize (Zea mays L.) Hybrids. Bangladesh Journal of Agricultural Research, 38, 335-341. https://doi.org/10.3329/bjar.v38i2.15894

[19] Chandel, U. and Guleria, S.K. (2019) Genetic Diversity Studies in Newly Developed Early Maturing Yellow Inbred Lines of Maize (Zea mays L.). Journal of Pharmacology and Phytochemistry, 8, 570-575.

[20] Singh, S.K., Singh, A.K., Singh, M.K., Jaiswai, P., Tigga, A., Kumar, A. and Bansgidhar (2019) Genetic Diversity of Bread Wheat (Triticum aestivum L.) Using Multivariate Analysis in Normal Irrigation and Drought Stress Conditions. Current Journal of Applied Science and Technology, 38, 1-9. https://doi.org/10.9734/cjast/2019/v38i630466

[21] Hoque, M.M., Asaduzzaman, M., Rahman, M.M., Zaman, S. and Begum, S.A. (2008) Genetic Divergence in Maize (Zea mays L). Bangladesh Journal of Agriculture, 9, 145-148. 
[22] Hasan, M.J., Rasul, M.G., Mian, M.A.K., Hasanuzzaman and Chowdury, M.M.H. (2000) Genetic Divergence of Yam (Diascorea sp.). Bangladesh Journal of Plant Breeding \& Genetics, 13, 7-11.

[23] Rahman, M.M., Rasul, M.G., Islam, M. and Sultana, S. (2000) Genetic Divergence in Chilli (Capsicum anum L.). Bangladesh Journal of Plant Breeding \& Genetics, 12, 7-11.

[24] Singh, R.K. and Chaudhary, B.D. (1985) Biometrical Methods in Quantitative Genetic Analysis. Kalyani Publishers, New Delhi, 318.

[25] Falconer, D.S. (1960) Introduction to Quantitative Genetics. Olive and Boid, London, 304.

[26] Moll, R.H., Salhuans, W.S. and Robinson, H.F. (1962) Heterosis and Genetic Diversity Invariety Crossed of Maize. Crop Science, 2, 197-198. https://doi.org/10.2135/cropsci1962.0011183X000200030005x

[27] Mian, M.A.K. and Bhal, P.N. (1989) Genetic Divergence and Hybrid Performance in Chickpea. Indian Journal of Genetics, 49, 119-129. 